\title{
COUP-TFIl regulates metastasis of colorectal adenocarcinoma cells by modulating Snail1
}

\author{
Y Bao ${ }^{\star}, 1,4, \mathrm{D} \mathrm{Gu}{ }^{2,4}$, W Feng ${ }^{1,4}$, X Sun ${ }^{1}$, X Wang ${ }^{1}$, X Zhang ${ }^{1}$, Q Shi ${ }^{1}, \mathrm{G} \mathrm{Cui}{ }^{1}, \mathrm{H} \mathrm{Yu}{ }^{1}, \mathrm{C}$ Tang ${ }^{1}$ and A Deng ${ }^{\star, 3}$ \\ ${ }^{1}$ First Affiliated Hospital, Huzhou Teachers College, the First People's Hospital of Huzhou, Huzhou 313000, China; ${ }^{2}$ Huzhou Central \\ Hospital, Huzhou 313000, China and ${ }^{3}$ Department of Laboratory Diagnostic, Changhai Hospital, Second Military Medical \\ University, Shanghai 200433, China
}

Background: Chicken ovalbumin upstream promoter-transcription factor II (COUP-TFII, also known as NR2F2) promotes metastasis by functioning in the tumour microenvironment; however, the role of COUP-TFIl in colorectal cancer remains unknown.

Methods: Human colon adenocarcinoma tissues were collected to test COUP-TFIl expression. Wound-healing and cell invasion assay were used to evaluate migration and invasion of cells. Chicken ovalbumin upstream promoter-transcription factor II and related protein expression was assessed by immunostaining, immunoblotting and real-time PCR assay. Tamoxifen-inducible COUP-TFII knockout mice were employed to test COUP-TFIl functions on colon cancer metastasis in vivo.

Results: Elevated expression of COUP-TFII in colorectal adenocarcinoma tissue correlated with overexpression of the Snail1 transcription factor. High COUP-TFIl expression correlated with metastasis and shorter patient survival. Chicken ovalbumin upstream promoter-transcription factor II regulated the migration and invasion of cancer cells. With Snail1, COUP-TFII inhibited expression of adherence molecules such as ZO-1, E-cadherin and $\beta$-catenin in colorectal cancer cells. Overexpression of COUPTFII was required for cancer cells to metastasise in vivo. Chicken ovalbumin upstream promoter-transcription factor II regulated the transcription and expression of Snail1 by directly targeting the Snail1 promoter and regulated associated genes.

Conclusions: Chicken ovalbumin upstream promoter-transcription factor II was crucial for colorectal cancer metastasis and regulated cell migration and metastasis in conjunction with Snail1. Chicken ovalbumin upstream promoter-transcription factor II was found to be a biomarker associated with patient survival and colorectal cancer metastasis.

Metastasis distinguishes malignant tumour cells from benign and normal cells and is the main cause of short survival and high mortality for cancer patients (Mareel, 1984). Metastasis is a complex process that includes invasion, survival and arrest in the bloodstream, and metastatic colonisation by cancer cells (Steeg, 2006). The first steps of metastasis are breaking away from neighbouring cells and the extracellular matrix, proteolytic degradation of surrounding tissue, and motility that propels a tumour cell through tissue.

Chicken ovalbumin upstream promoter-transcription factor II (COUP-TFII) is a key molecule in the development of cancers including cancer of the breast, lung, and prostate, and adrenal cancer. Chicken ovalbumin upstream promoter-transcription factor II is involved in the regulation of cell migration in cancer invasion and metastasis in lung and breast cancers. Chicken ovalbumin upstream promoter-transcription factor II is a member of the nuclear hormone-receptor superfamily (Sugiyama et al, 2000). It is highly expressed in the mesenchyme and is critical for mouse development of heart, skeletal muscle, and vein (Pereira et al, 1999; Lee et al, 2004; You et al, 2005; Lee et al, 2012). Recently, COUP-TFII was found to be expressed in many tumour cell lines (Kieback et al, 1993) including from human endometrial, lung, pancreatic, and breast cancers, and from adrenal tumours (Kieback et al, 1996; Wu et al, 1997; Shibata et al, 1998; Prahalad et al, 2010; Qin et al, 2010). Chicken ovalbumin upstream promoter-transcription factor II is not expressed in terminally differentiated epithelial cells but is important in mesenchymalendothelial interactions, angiogenesis, and tumour growth and

\footnotetext{
*Correspondence: Dr Y Bao; E-mail: baoying2222@126.com or Professor A Deng; E-mail: amdeng70@163.com
}

${ }^{4}$ These authors contributed equally to this work. 
metastasis by inhibition of TGF- $\beta$-induced growth barrier (Qin et $a l, 2010)$ and negative regulating transactivation of androgen receptor (Song et al, 2012). In adult xenografted mice, COUP-TFII compromises neoangiogenesis and suppresses tumour growth (Qin et al, 2010). Chicken ovalbumin upstream promoter-transcription factor II functions as a transcription factor by promoting or repressing tissue-specific gene expression (De Martino et al, 2004; Litchfield and Klinge, 2012). It decreases expression of aldehyde dehydrogenase 2 family $(A L D H 2)$, apolipoprotein A-I (APOA1), apolipoprotein A-IV (APOA4), GATA binding protein 6 (GATA6), and haemoglobin, epsilon 1 (HBE1). However, COUP-TFII increases expression of angiopoietin 1 (ANGPT1), HNF1 homeobox A (HNF1A), VEGFR2; kinase insert domain receptor (a type III receptor tyrosine kinase; $H D R$ ), and Hepatocyte nuclear factor 4, alpha (HNF4A). However, the roles and mechanisms of action of COUP-TFII in colon cancer development remain largely unknown.

Snaill is a member of the Snail family of transcription factors that induces epithelial-to-mesenchymal transitions and accelerates tumour metastasis via both enhanced invasive ability and regulation of E-cadherin and immunosuppression (Cano et al, 2000; Li et al, 2007; Kudo-Saito et al, 2009). Xu et al (2013) reported that Snail1 regulates hepatocellular carcinoma malignancy by binding to and repressing the promoter of the Cezanne2 gene. Snaill facilitates breast cancer metastasis through stabilisation by the collagen receptor discoidin domain receptor 2 (Zhang et al, 2013).

Adult mice lacking COUP-TFII are largely normal without visible defects (Pereira et al, 1999). Therefore, in this study, we employed COUP-TFII knockout mice as a colon cancer model. We found that both COUP-TFII and Snaill expression are enhanced in human colon cancer tissues. This aberrant COUP-TFII overexpression correlated with survival of colon cancer patients, suggesting that COUP-TFII function in colon cancer development. Overexpression of COUP-TFII promoted colon cancer cell metastasis by enhancing Snaill expression.

\section{MATERIALS AND METHODS}

Tissue collection. Human tissue use was approved by the Institutional Review Board and the Local Ethics Committee of the First People's Hospital of Huzhou and was done in accordance with international guidelines for the use of human tissues. Protocols used in the study were approved by the hospital's Protection of Human Subjects Committee. Fresh tissue samples of 326 colon adenocarcinoma patients with adjacent non-cancerous tissues were collected from surgical resections and endoscopic biopsies in the Department of Gastrointestinal Surgery in the First People's Hospital of Huzhou (Hangzhou, China). All samples were from patients who gave informed consent to use excess pathological specimens for research. All tissues had a definitive pathological diagnosis.

Cell culture. The human colon adenocarcinoma cell lines LOVO and HT29 and the human intestinal epithelium cell line HIEC were from the American Type Culture Collection and were maintained as recommended. Cells were maintained on plates at $37^{\circ} \mathrm{C}$, with $5 \% \mathrm{CO}_{2}$ in RPMI 1640 (GIBCO, Grand Island, NY, USA) supplemented with $10 \%$ fetal bovine serum, 100 units per millilitres penicillin and $0.1 \mathrm{mg} \mathrm{ml}^{-1}$ streptomycin.

Cell transfection and luciferase assay. Cell transfection was as previously described (Wang et al, 2013) using $5 \mu \mathrm{g} \mathrm{ml}^{-1}$ small hairpin (sh)RNA against COUP-TFII or Snail1, Snail-overexpressing plasmid, COUP-TFII-overexpressing plasmid or empty plasmid. G418 or puromycin selection was applied $24 \mathrm{~h}$ after transfection. For luciferase assays, the Snail1, MMP2 and MMP9 (matrix metalloproteinases 2 and 9) promoter fragment was cloned into the
pGL3-Basic (pGL3/-1866) plasmid. Luciferase assays used DualLuciferase assay kits (Promega, Madison, WI, USA) according to the manufacturer's instructions at $48 \mathrm{~h}$ post transfection. All transfections were carried out in triplicate and repeated at least three times.

Wound-healing assay. For monolayer wound-healing assays, $2 \times 10^{5}$ LOVO and HT29 cells were plated in six-well plates. At $100 \%$ confluence, cells were cultured in serum-free medium for $24 \mathrm{~h}$. Then two parallel, $1 \mathrm{~mm}$ wounds were made using a pipette tip. Wound size after $0,1,2$, or 3 days was measured using Zeiss LSM Image Browser software, version 3.1 (Mississauga, ON, Canada), in three independent experiments.

Cell invasion assay. Invasion assays using BioCoat Matrigel Invasion Chambers (Becton Dickinson, Franklin Lakes, NJ, USA) were done according to the user's manual. In brief, $5 \times 10^{3}$ LOVO and HT2 29 cells in $300 \mu$ l of DMEM containing $0.2 \%$ bovine serum albumin (BSA) were seeded into upper chambers and incubated at $37^{\circ} \mathrm{C}$ for $24 \mathrm{~h}$. Cells that penetrated Matrigel-coated 24 well plates (Corning, Tewksbury, MA, USA) were fixed, stained and counted at a magnification of $400 \times$ in 10 randomly selected fields, and the mean number of cells per field was recorded. The experiments were repeated three times.

Immunofluorescence. Cells were washed with PBS, fixed in $4 \%$ paraformaldehyde, permeabilised with $0.1 \%$ Triton X-100 (Sigma, Steinteim, Switzerland), and blocked in 2\% BSA before staining with anti-phalloidin (\#12935), anti-E-cadherin (\#4295; Cell Signaling, Denvers, MA, USA), anti- $\beta$-catenin (\#13727) or ZO-1 antibodies (\#8193; Santa Cruz Biotechnology, San Jose, CA, USA), all in 1:50 dilution. Images were collected with a confocal microscope (Leica Microsystems, Wetzlar, Germany).

Immunohistochemistry. Paraffin sectioning and staining of mice tumour tissues was carried out according to standard protocols (Wang et al, 2013) with anti-E-cadherin or anti- $\beta$-catenin (\#13727; Cell Signaling), both in 1:50 dilution. Streptavidin-conjugated secondary antibody was visualised with $\operatorname{DAB}\left(3,3^{\prime}\right.$-diaminobenzidine). Images were analysed with an Olympus microscope (Tokyo, Japan) under light field.

Western blot analysis. Tissue protein lysis was prepared as described (Wang et al, 2009). Cell lysates were generated with RIPA lysis buffer (Guangzhou Fans Biotechnology, Co. Ltd., Guangzhou, China). Nuclear protein was extracted by using NE-PER Nuclear and Cytoplasmic Extraction Reagents (Thermo Scientific, Rockford, IL, USA). Protein concentration was determined by a standard BCA assay, and $60 \mu \mathrm{g}$ total cell lysates or nuclear extracts were separated by sodium dodecyl sulphate polyacrylamide gel electrophoresis (SDS-PAGE). Proteins were transferred onto PVDF membranes (Amersham Biosciences, Buckinghamshire, UK), and membranes were probed with anti-Snail1 (sc-28199; Santa Cruz Biotechnology), anti-MMP2 (\#13132), anti-MMP9 (\#3852; Cell Signaling), anti-COUP-TFII (PP-H7147-00; Perseus Proteomics, Tokyo, Japan), all in $1: 1000$ dilution, or anti-tubulin (ab126165; Abcam, Cambridge, MA, USA) (1:2000 dilution) and visualised with horseradish peroxidase-conjugated secondary antibody (Santa Cruz Biotechnology) and ECL kits (Amersham Pharmacia Biotech, Buckinghamshire, UK). Protein bands were quantified by Total lab software (Nonlinear Dynamics, Newcastle upon Tyne, UK).

Real-time PCR. Total RNA was extracted with TRIzol (Invitrogen, Paisley, UK) according to the manufacturer's protocol and reverse transcribed using Reverse Transcription Reagents (Invitrogen). Real-time (RT) PCR was performed on an Applied Biosystems 7300 Real Time PCR system (Foster City, CA, USA) using SYBR Green (Foster City, CA, USA) following standard protocols. All mRNA quantities were normalised 
against the housekeeping gene $c y c A$. Primers were Snail-1-F, $5^{\prime}$-AAGGATCTCCAGGCTCGAAAG-3'; Snail-1-R, 5' -GCTTCGG ATGTGCATCTTGA-3'; $c y c A-\mathrm{F}, 5^{\prime}$-TATCTGCACTGCCAAGAC TGAGTG-3'; and cycA-R, $5^{\prime}$-CTTCTTGCTGGTCTTGCCAT TCC- $3^{\prime}$.

Pull-down assay and gelatin zymography. These procedures have been described previously (Nie et al, 2007). In brief, cells were cultured in six-well plates. After transfection, serum-free media supplemented with purified proMMP2 or proMMP9 in fetal bovine serum $(5 \% \mathrm{v} / \mathrm{v})$ was added to cells. After $24 \mathrm{~h}$, conditioned media were collected and centrifuged and subjected to analyse by SDS-PAGE impregnated with $1 \mathrm{mg} \mathrm{ml}^{-1}$ gelatin as described.

For pull-down assay, cells were transfected with Flag-tagged COUP-TFII. Cells were lysed and cell extracts were cleared and incubated with beads at $4{ }^{\circ} \mathrm{C}$ overnight. The beads were washed three times and boiled in SDS sample buffer. The prepared samples were analysed by western blotting with anti-Flag antibody.

The lysates were centrifuged $(14000 \mathrm{~g}, 20 \mathrm{~min})$ to remove debris, and the resulting supernatants were immunoprecipitated and blotted as described (Gelfi et al, 2002).

Chromatin immunoprecipitation. Chromatin immunoprecipitation (ChIP) assays were performed as described as previously (Wang et al, 2013) according to the protocol provided by Millipore (Watford, UK). All results were from three independent samples.

Electrophoretic mobility shift assay. Nuclear proteins from LOVO cells transfected with the indicated vectors were extracted using NE-PER kits (Pierce, Madison, WI, USA). Complementary oligonucleotides were annealed and end-labelled with [c-32P]ATP. Binding reactions were performed and analysed using 5\% nondenaturing gels. For supershift studies, antibodies against Snail-1 (Santa Cruz Biotechnology) were added for preincubation on ice, and DNA-protein complexes were visualised by autoradiography.

Animal experiments. The study on mice was conducted after approval from the Institutional Animal Ethics Committee (IAEC) of the First People's Hospital of Huzhou, endorsed by the Committee for the Purpose of Control and Supervision of Experiments on Animals (CPCSEA), government of Zhejiang province. COUP-TFII-null mutant induces embryonic lethality. Therefore, we used tamoxifen-inducible knockout system to generate COUP-TFII ${ }^{-1-}$ mice following Tsai's method (Xie et al, 2011). Generation of COUP-TFII flox/flox C57BL/6J mice was previously described (Pereira et al, 1999). COUP-TFII ${ }^{-1-}$ mice were generated by mating COUP-TFII flox/flox mice with ROSA26 $6^{\text {CRE-ERT2/ }+}$ mice. The pregnant female mice were given tamoxifen to ablate the COUP-TFII gene. Models of colitis-related carcinogenesis were generated as described previously (Wang et al, 2009): mice were given a single intraperitoneal administration of $15 \mathrm{mg} \mathrm{kg}^{-1}$ body weight of 1,2-dimethylhydrazine (DMH), followed by 1 week of oral exposure to $2 \%$ dextran sulphate sodium (DSS) in the drinking water. At week 40, mice were killed and colons and livers were inspected for macroscopic pathological lesions.

Liver metastasis models of colon cancer were generated as described previously (Hamada et al, 2008). LOVO cells were trypsinised and suspended in serum-free medium at $2 \times 10^{5}$ cells per millilitres. Experimental liver metastases were generated by intrasplenic injection of $10^{4}$ cells $(50 \mu \mathrm{l}$ of cell suspension). Mice were killed 3 weeks later and livers were removed.

Statistical analysis. Data shown are the mean of at least three independent experiments with standard deviation (s.d.), and were analysed using SPSS version 13.0 software (Armonk, NY, USA). Student's $t$-test was used to compare data. $P$ values $<0.01$ were considered statistically significant. Correlation between
COUP-TFII and Snaill expression was analysed by Spearman's rank correlation coefficient analysis.

\section{RESULTS}

Chicken ovalbumin upstream promoter-transcription factor II and Snail1 are overexpressed in colon adenocarcinoma. Expression of COUP-TFII and Snaill was measured in tumour samples and adjacent normal tissues from 326 colon adenocarcinoma patients. The average patient age was 57.2 years. Chicken ovalbumin upstream promoter-transcription factor II levels were significantly increased in carcinoma tissue samples compared to adjacent normal controls in 58.6\% (191 out of 326) of analysed patients (Figure 1A and B). Snail1 expression was elevated in 54\% (177 out of 326 ) of carcinoma samples. In $66.7 \%$ (118 out of 177) of patient samples in which Snail1 overexpressed, COUP-TFII was also overexpressed (Figure 1C). Chicken ovalbumin upstream promoter-transcription factor II showed a positive correlation with Snaill expression during different clinical stages of colon adenocarcinoma development $(R=0.606)$. In total, 64.5\% (118 out of 183) patients who showed vessel invasion were COUP-TFII overexpression. Meanwhile, 68\% (113 out of 166) patients of metastasis at T3,4 stage showed COUP-TFII overexpression (Table 1). These results suggested that both COUP-TFII and Snaill either might be important in colon adenocarcinoma development, or might be a prognostic marker. Expression level of COUP-TFII might relate to metastasis of tumours. Moreover, COUP-TFII overexpression might be correlated to Snaill overexpression. Five-year follow-up after surgery and/or chemotherapy suggested that patients with high tumour expression of COUPTFII had a shorter survival than patients whose tumours had low COUP-TFII levels (Figure 1D). In the investigation on the regulation of COUP-TFII on Snaill in colon cancer cells in vitro, we found that repression of COUP-TFII decreased Snail expression. However, overexpression of COUP-TFII increased Snaill expression. However, neither overexpression nor repression of Snaill affected COUP-TFII expression, indicating that COUPTFII is an upstream effector of Snail1 (Figure 1E).

Chicken ovalbumin upstream promoter-transcription factor II regulation of colon cancer cell invasion is dependent on Snail1. To study the effect of COUP-TFII on cell motility, we used an in vitro wound-healing assay, measuring the extent of cell migration into a scratched area. Migration of LOVO and HT29 cells was inhibited in cells in which COUP-TFII or Snail1 expression was repressed using shRNA. Migration inhibition was partially rescued by overexpression of Snaill in COUP-TFII knockdown cells (Figure 2A and B). Moreover, the migration distance was decreased when Snail1 was depleted even in COUPTFII overexpression cells.

We used a Matrigel transmembrane invasion assay to study the invasive properties of LOVO and HT29 cells. Repression of COUP-TFII or Snaill reduced the invasiveness of the colon cancer cells. Introduction of a Snail-overexpressing plasmid into cells induced invasiveness in COUP-TFII knockdown cells (Figure 2C and D). The invasiveness was inhibited when Snail1 was depleted even in COUP-TFII overexpression cells. These results suggested that COUP-TFII interfered with colon cancer cell migration and invasion capacity and this effect depended on Snail1.

Chicken ovalbumin upstream promoter-transcription factor II regulates metastasis of colon cancer in vivo. To study COUPTFII function in vivo, we generated COUP-TFII knockout mice by using tamoxifen-inducible knockout system (Xie et al, 2011) and used them as DMH/DSS-induced mouse models of colonic carcinogenesis. Body weight was slightly decreased in DMH/ DSS-treated mice compared to normal mice. The body weight of 
A

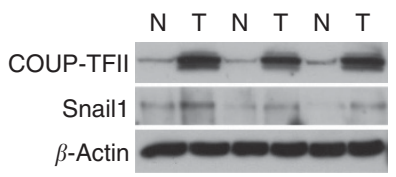

B

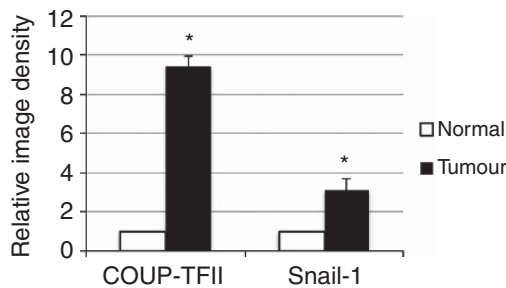

C

Expression of COUP-TFII and Snail1 in human colon adenocarcinoma tissue

\begin{tabular}{cccc}
\hline & \multicolumn{2}{c}{ COUP-TFII } & \\
\cline { 2 - 3 } Snail1 & Negative & Positive & Total \\
\hline Negative & 76 & 73 & 149 \\
Positive & 49 & 118 & 177 \\
Total & 125 & 191 & 326 \\
\hline
\end{tabular}

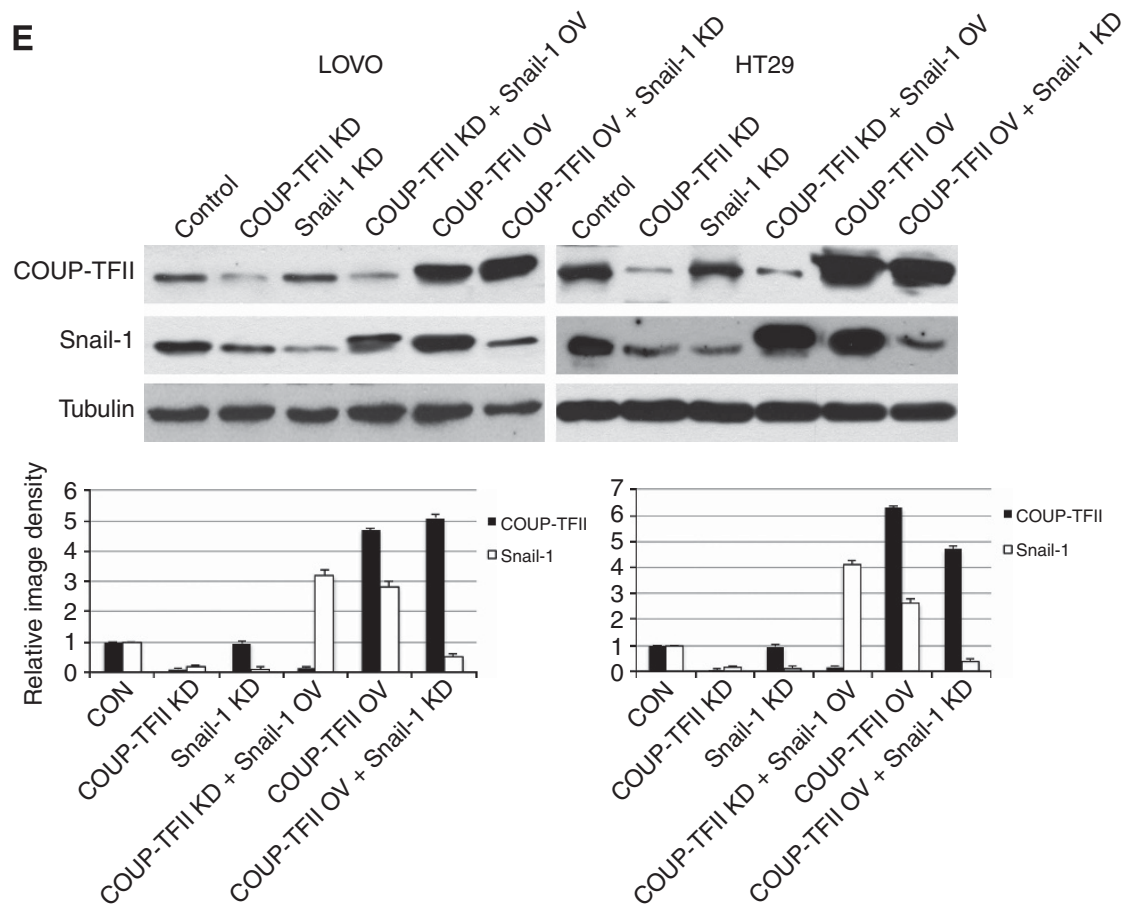

Figure 1. Chicken ovalbumin upstream promoter-transcription factor II and Snail1 are overexpressed in colon adenocarcinoma tissue. (A) Expression of COUP-TFII and Snail-1 in human colorectal adenocarcinoma tissue. Western blots were used to determine expression of COUP-TFII and Snail1 in human colorectal adenocarcinoma tissue. Lanes contain equal amounts of nuclear protein from colorectal adenocarcinoma tissue (T) and paired normal tissue (N). (B) Quantification of image density from A. * $P<0.01$ compared to normal. (C) Representive images were shown for the expression of COUP-TFII and Snail1 in 326 human colorectal adenocarcinoma tissue samples, determined by western blot. (D) Survival curves for colorectal adenocarcinoma patients with either high or low COUP-TFII $(P<0.01)$. (E) Human colon adenocarcinoma LOVO or HT29 cells stably expressing control vector (CON), shRNA against COUP-TFII (COUP-TFII KD), shRNA against Snail1 (Snail-1 KD), COUP-TFII KD + Snail-1 overexpressing (Snail-1 OV), COUP-TFIl overexpressing (COUP-TFII OV), or COUP-TFII OV + Snail-1 KD were cultured. Expression of COUP-TFII and Snail1 by western blot. Tubulin was the loading control. Density of bands were quantified.

COUP-TFII $^{-1-}$ mice $(n=10,5$ male and 5 female) was not different than COUP-TFII ${ }^{+1+}$ mice. There was no difference between male and female mice. In both control and COUP-TFII ${ }^{-1-}$ mice, the incidence of tumours was $100 \%$ and the incidence of colorectal tumours was similar (Table 2). Metastatic tumours in the liver were observed in COUP-TFII ${ }^{+/+}$mice treated with DMH/ DSS after 40 weeks (Figure 3A). No metastatic tumours were found in the livers of COUP-TFII ${ }^{-1}$ mice treated with DMH/DSS, suggesting that COUP-TFII was crucial for colon cancer metastasis, not for the formation of tumours.

A deficiency in cell-to-cell adhesion is important for metastasis (Wang et al, 2012). We therefore used immunohistochemistry on mouse tumour tissue samples to test the expression of two markers of the adhesion belt junction between cells, E-cadherin and $\beta$-catenin. No E-cadherin or $\beta$-catenin was observed in tumours from wild-type mice, but E-cadherin and $\beta$-catenin were clearly observed in tumours from COUP-TFII ${ }^{-1-}$ mice (Figure $3 \mathrm{~B}$ ). We also tested for expression of MMP2 and MMP9, which are also important molecules for tumour metastasis. Figure 3E shows that expression of MMP2 and MMP9 was reduced in COUP-TFII ${ }^{-1-}$ tumours compared to tumours from wild-type mice.

To further study the function of COUP-TFII in metastasis of colon cancer in vivo, a liver metastasis model was generated by injecting wild-type or COUP-TFII-depleted LOVO cells into 


\begin{tabular}{|c|c|c|}
\hline & \multicolumn{2}{|c|}{ No. of patients (\%) } \\
\hline & COUP-TFII (-) & COUP-TFII $(+)$ \\
\hline \multicolumn{3}{|c|}{ Age (year) } \\
\hline $\begin{array}{l}\leqslant 60 \\
>60\end{array}$ & $\begin{array}{l}61(42.7) \\
74(40.4)\end{array}$ & $\begin{array}{r}82(57.3) \\
109(59.6)\end{array}$ \\
\hline \multicolumn{3}{|l|}{ Gender } \\
\hline \begin{tabular}{|l} 
Male \\
Female
\end{tabular} & $\begin{array}{l}67(40.4) \\
68(42.5)\end{array}$ & $\begin{array}{l}99(59.6) \\
92(57.5)\end{array}$ \\
\hline \multicolumn{3}{|c|}{ Vessel invasion } \\
\hline \begin{tabular}{|l|} 
Negative \\
Positive
\end{tabular} & $\begin{array}{l}70(49.0) \\
65(35.5)\end{array}$ & $\begin{array}{r}73(51.0) \\
118(64.5)\end{array}$ \\
\hline \multicolumn{3}{|l|}{ Site } \\
\hline $\begin{array}{l}\text { Colon } \\
\text { Rectum }\end{array}$ & $\begin{array}{l}67(39.2) \\
68(41.7)\end{array}$ & $\begin{array}{l}94(60.8) \\
97(58.3)\end{array}$ \\
\hline \multicolumn{3}{|c|}{ Differentiation } \\
\hline $\begin{array}{l}\text { Well } \\
\text { Moderate } \\
\text { Poor }\end{array}$ & $\begin{array}{l}31(35.2) \\
49(44.5) \\
55(43.0)\end{array}$ & $\begin{array}{l}57(64.8) \\
61(55.5) \\
73(57.0)\end{array}$ \\
\hline \multicolumn{3}{|c|}{ Stage of tumours } \\
\hline $\begin{array}{l}1,2 \\
3,4\end{array}$ & $\begin{array}{l}82(52.9) \\
53(31.0)\end{array}$ & $\begin{array}{r}78(47.1) \\
113(68.0)\end{array}$ \\
\hline \multicolumn{3}{|c|}{ Lymph nodes } \\
\hline \begin{tabular}{|l|} 
Negative \\
Positive
\end{tabular} & $\begin{array}{l}86(58.5) \\
49(29.0)\end{array}$ & $\begin{array}{r}71(41.5) \\
120(71.0)\end{array}$ \\
\hline
\end{tabular}

mouse spleens. The number of metastatic tumours was reduced in mice injected with COUP-TFII-depleted LOVO cells compared to control LOVO cells (Figure $3 \mathrm{~F}-\mathrm{H}$ ). The average survival time for mice injected with COUP-TFII-depleted LOVO cells was $42.4 \pm 3.5$ days compared to $21.5 \pm 2.6$ days for mice injected with control LOVO cells. These results suggested that COUP-TFII was crucial for colon cancer metastasis, possibly through regulation of cell junction formation and MMP expression.

Chicken ovalbumin upstream promoter-transcription factor II regulates colon cancer cell invasion by regulating cadherins and MMPs. Given our results on the function of COUP-TFII in metastasis of colon cancer in vivo and in vitro, we hypothesised that COUP-TFII regulated colon cancer cell metastasis through effects on cell-cell contacts. As Figure 4 shows, when confluent LOVO cells were incubated with high concentrations of calcium (1 mM), COUP-TFII or Snail1 knockdown LOVO cells became tightly attached to each other within $12 \mathrm{~h}$, while control LOVO cells did not. In COUP-TFII-deficient or Snail1-deficient LOVO cells, belt-like junctions containing the adherens junction proteins E-cadherin and $\beta$-catenin were established $12 \mathrm{~h}$ after addition of calcium (Figure $4 \mathrm{~A}$ ). In contrast, only weak signals were detected for E-cadherin and $\beta$-catenin in control LOVO cells. Similarly, the tight junction protein ZO-1 was seen to form belt-like structures at the membranes of COUP-TFII-deficient or Snaill-deficient LOVO cells, but only at punctate contacts between control cells (Figure 4A). These potential cell-to-cell junctions between COUP-TFII knockdown cells were not seen in cells transfected with a Snail1-overexpressing plasmid. These results suggested that COUP-TFII regulated colon cancer cell-to-cell junctions through Snaill.

The expression and activity of MMP2 and MMP9 were inhibited when COUP-TFII expression was suppressed (Figure 4B). Direct binding of COUP-TFII to the MMP2 and MMP9 promoters was seen in pull-down assays with nuclear lysates. The association of COUP-TFII with oligonucleotides containing the COUP-TFII consensus sequences was investigated by western blotting (Figure 4C). To examine the effect of COUPTFII promoter binding on MMP2 and MMP9 transcription, we assessed the potential binding element of COUP-TFII by cotransfection of a COUP-TFII overexpression or shRNA plasmid with pGL3/ - 1866, which contains MMP2 or MMP9 promoter fragments, into LOVO cells. Promoter activity was tested by luciferase assay. The results showed that activity of the MMP2 and MMP9 promoters was induced by transfection with a plasmid expressing COUP-TFII, but the activity decreased when COUPTFII was repressed (Figure 4D). Collectively, these results provided evidence that COUP-TFII activated the genes for MMP2 and MMP9 by directly binding to their promoters.

Overexpression of COUP-TFII results in tumourigenesis of intestinal epithelial cells. Compared to cells from the normal intestinal epithelial line HIEC, colon cancer cells significantly overexpressed COUP-TFII (Figure 5A). To determine the effect of COUP-TFII on tumourigenesis of intestinal epithelial cells, we transformed HIEC cells with a COUP-TFII-overexpressing plasmid. The transformed cells showed high COUP-TFII and Snail expression (Figure 5B). E-cadherin expression was reduced, but vimentin expression that was identified as epithelial mesenchymal transition marker, was increased in COUP-TFII-overexpressing cells. Migration and invasion were also enhanced (Figure 5C and D) when cells were transfected with COUP-TFII plasmid. Real-time PCR showed that Snaill mRNA was elevated in LOVO and HT29 cells and overexpression of COUP-TFII enhanced expression of Snail1 in HIEC cells (Figure 5E and F).

Chicken ovalbumin upstream promoter-transcription factor II positively regulates Snaill expression through direct transcriptional activation. Since COUP-TFII enhanced Snaill expression at both the mRNA and protein levels, we tested whether Snail1 was a direct target of COUP-TFII. Chromatin immunoprecipitation assays showed binding of COUP-TFII to two distinct regions of the Snail1 promoter harbouring COUP-TFII-binding sites. Binding was abolished by knockdown of COUP-TFII, but enhanced by overexpression of COUP-TFII (Figure 6A and B).

Next, we investigated the functional consequences of COUPTFII and Snail1 interaction. EMSAs with a fluorescently labelled Snail1 consensus oligonucleotide (FAM-Snail1) were performed using equal amounts of nuclear extracts from cells from control non-transfected cells, Snail1 knockdown, or COUP-TFIIoverexpressing (COUP-TFII OV) cells (Figure 6C). Band shifts were observed with nuclear extracts from control or COUP-TFIIoverexpressing cells, but not COUP-TFII knockdown cells. Bands observed using COUP-TFII-overexpressing extracts were stronger than bands obtained using control extracts. This result suggested that Snaill was available for binding to its DNA target sequences when COUP-TFII was overexpressed.

To identify Snaill target genes, we performed ChIP sequence assays using anti-Snaill on control and COUP-TFII knockdown cells. The relative enrichment of Snaill occupancy of 16 potential target genes was determined using RT PCR. Increases in Snail 1 occupancy of predicted binding sites at $J U N B$, cytochrome P450, 
A
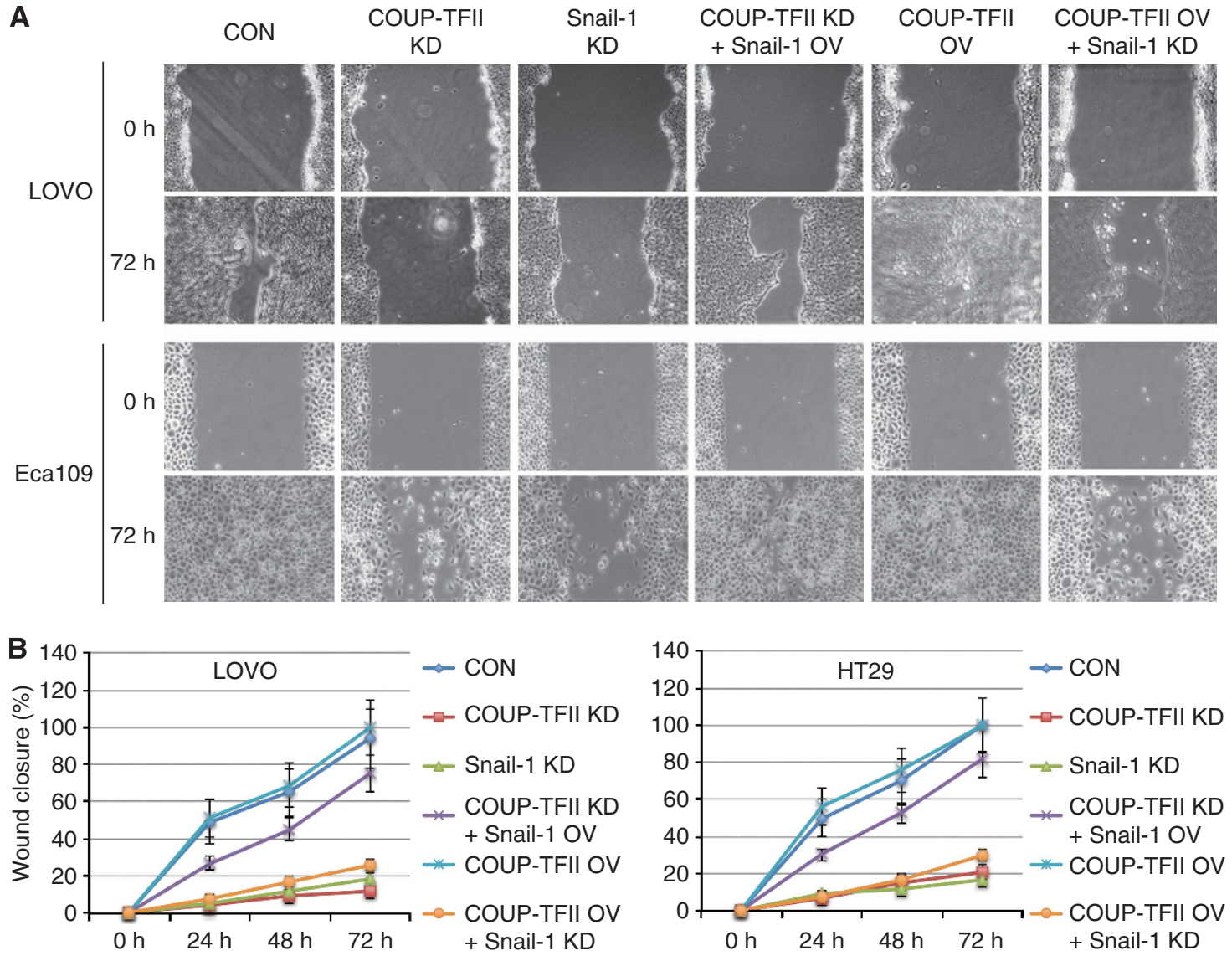

C
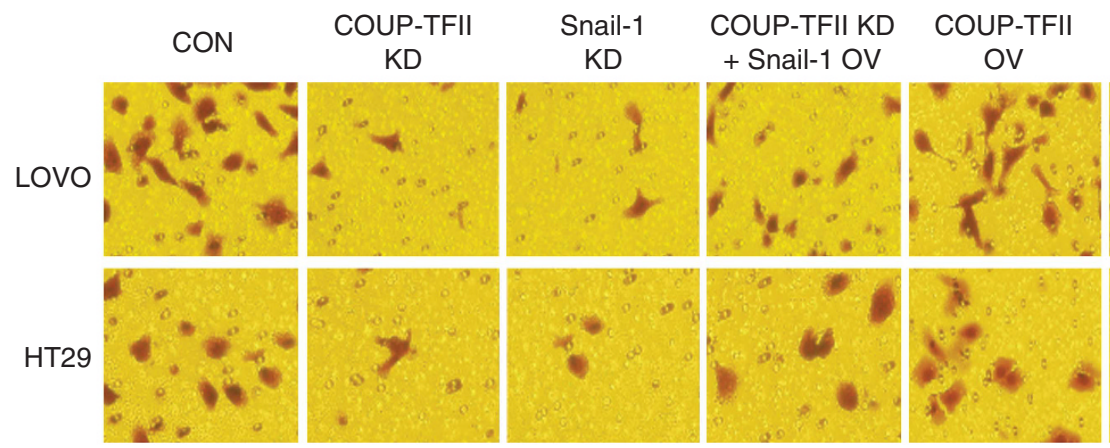

COUP-TFII OV + Snail-1 KD

D

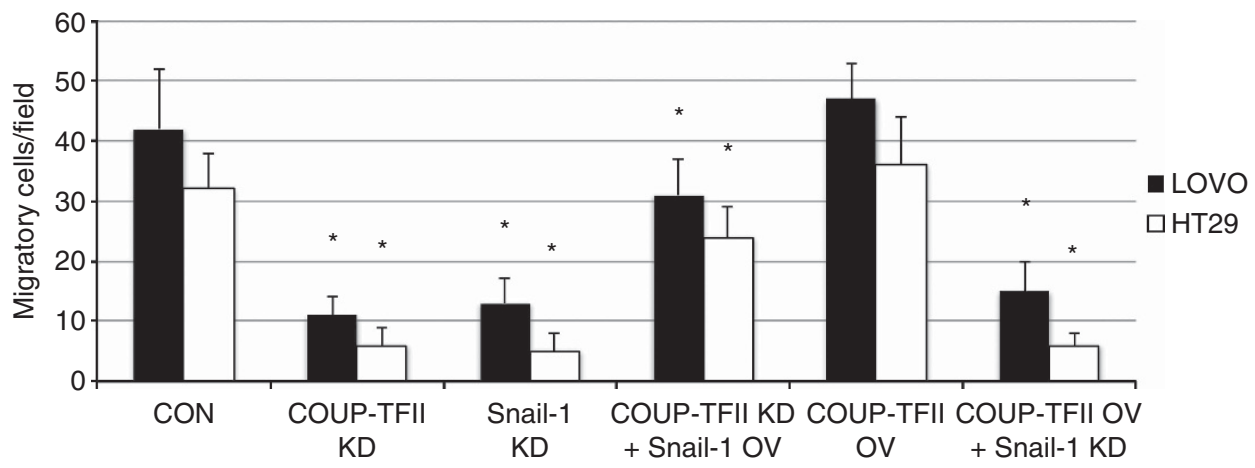

Figure 2. Chicken ovalbumin upstream promoter-transcription factor II regulation of colon cancer cell invasion is dependent on Snail1. Human colon adenocarcinoma LOVO or HT29 cells were transfected and cultured as described in Figure 1E. (A and B) Wound-healing assay with LOVO or HT29 cells transfected with indicated vectors showing wound width and percent closure of the original wound from triplicate plates. ${ }^{\star} P<0.01$ compared to the same time points for control non-transfected (CON) wounded LOVO or HT29 cells. (C and D) LOVO or HT29 cells transfected with indicated vectors that penetrated Matrigel-coated filters. Quantitation is the mean number of cells in 10 random microscope fields. Data are mean \pm s.d., $n=3 ;{ }^{\star} P<0.01$. 


\section{Table 2. DMH/DSS-induced colon cancer mice model}

\begin{tabular}{|c|c|c|c|c|c|c|}
\hline Group & $n$ & Body weight (g) & Survival rate (\%) & Incidence of tumour & Numbers of tumour/mouse & Incidence of metastasis \\
\hline Wild type & 10 & $39.4 \pm 4.1$ & 50 & 10 & $3.2 \pm 2.1$ & 4 \\
\hline COUP-TFII $^{-1-}$ & 10 & $40.6 \pm 3.7$ & 90 & 10 & $3.1 \pm 1.5$ & 0 \\
\hline
\end{tabular}

A

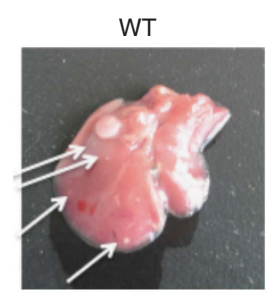

C

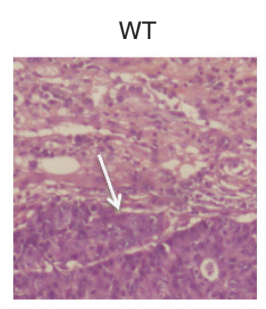

COUP-TFII-1-

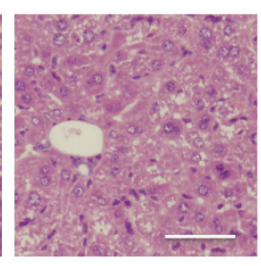

E
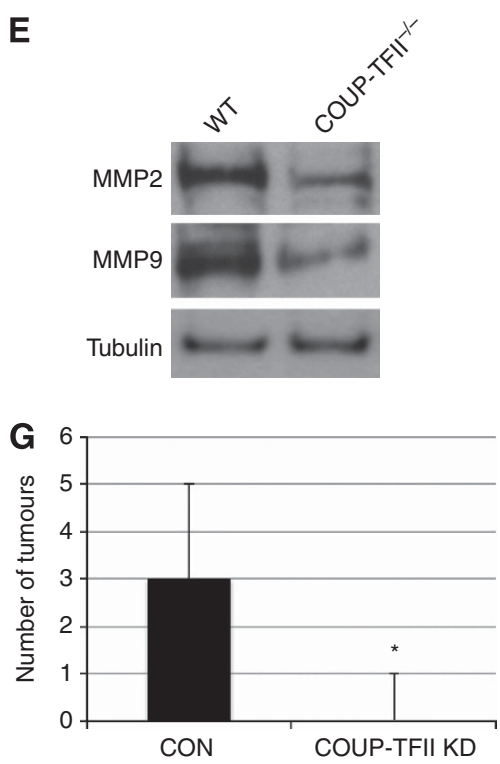

B

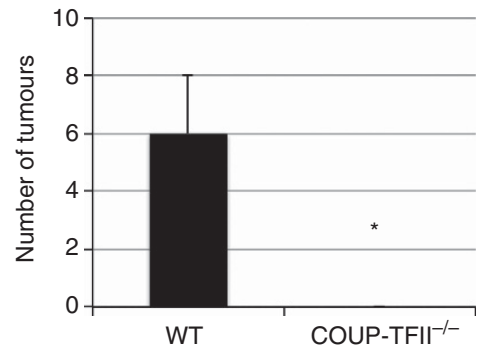

D

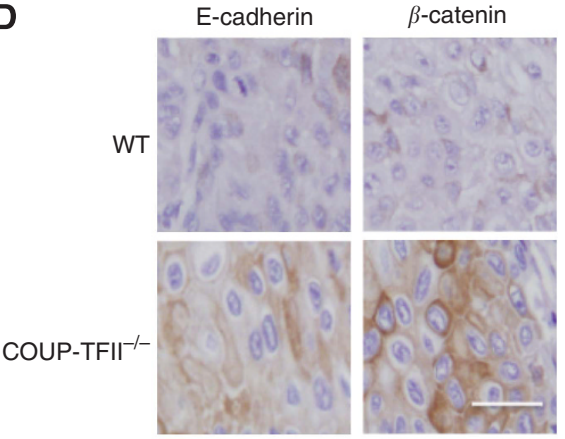

$\mathbf{F}$

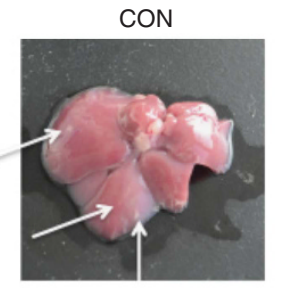

COUP-TFII KD

H

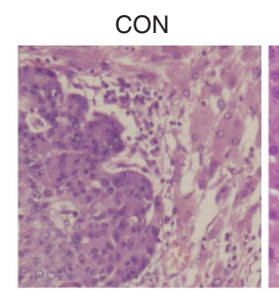

COUP-TFII KD

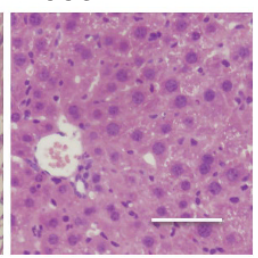

Figure 3. Chicken ovalbumin upstream promoter-transcription factor II regulates metastasis of colon cancer in vivo in mice. Wild-type (WT) or COUP-TFII ${ }^{-1-}$ mice were used to generate DMH/DSS-induced colon cancer models. (A) Typical appearance of metastatic foci on control livers (arrows). (B) Number of metastatic foci from A were calculated. ${ }^{*} P<0.01$ compared to WT. (C) Haematoxylin and eosin (H\&E) staining for liver tissue. The arrow shows the tumour. Bar, $200 \mu \mathrm{m}$. (D) Immunohistochemistry was used to evaluate expression of E-cadherin and $\beta$-catenin from collected colon adenocarcinoma tissues. Bar, $50 \mu \mathrm{m}$. (E) Western blot showing expression of MMP2 and MMP9 in tumours from wild-type mice (WT) or COUP-TFII ${ }^{-1-}$ mice (COUP-TFII ${ }^{-1-}$ ). (F) Control LOVO cells (CON) or COUP-TFll-depleted LOVO cells (COUP-TFII KD) were injected into spleens of nude mice. After 30 days, mice were killed and metastatic foci (arrows) on livers were examined. (G) Number of metastatic foci from F was calculated. ${ }^{\star} P<0.01$ compared to CON. (H) H\&E staining for liver tissue. Bar, $200 \mu \mathrm{m}$.

family 7, subfamily a, polypeptide 1 (Cyp7a1; Yamazaki et al, 2013), $\beta$-catenin (ctnnb1-b), PPARg1 (Pparg1), Ucp3, hTERT, Mmp2, Otx2, E-cadherin (Cdh1) and N-cadherin (Cdh2) were tested in COUP-TFII knockdown cells relative to control cells (Figure 6D), suggesting that under control of COUP-TFII, Snail1 might be able to regulate these genes by either activation or 
A

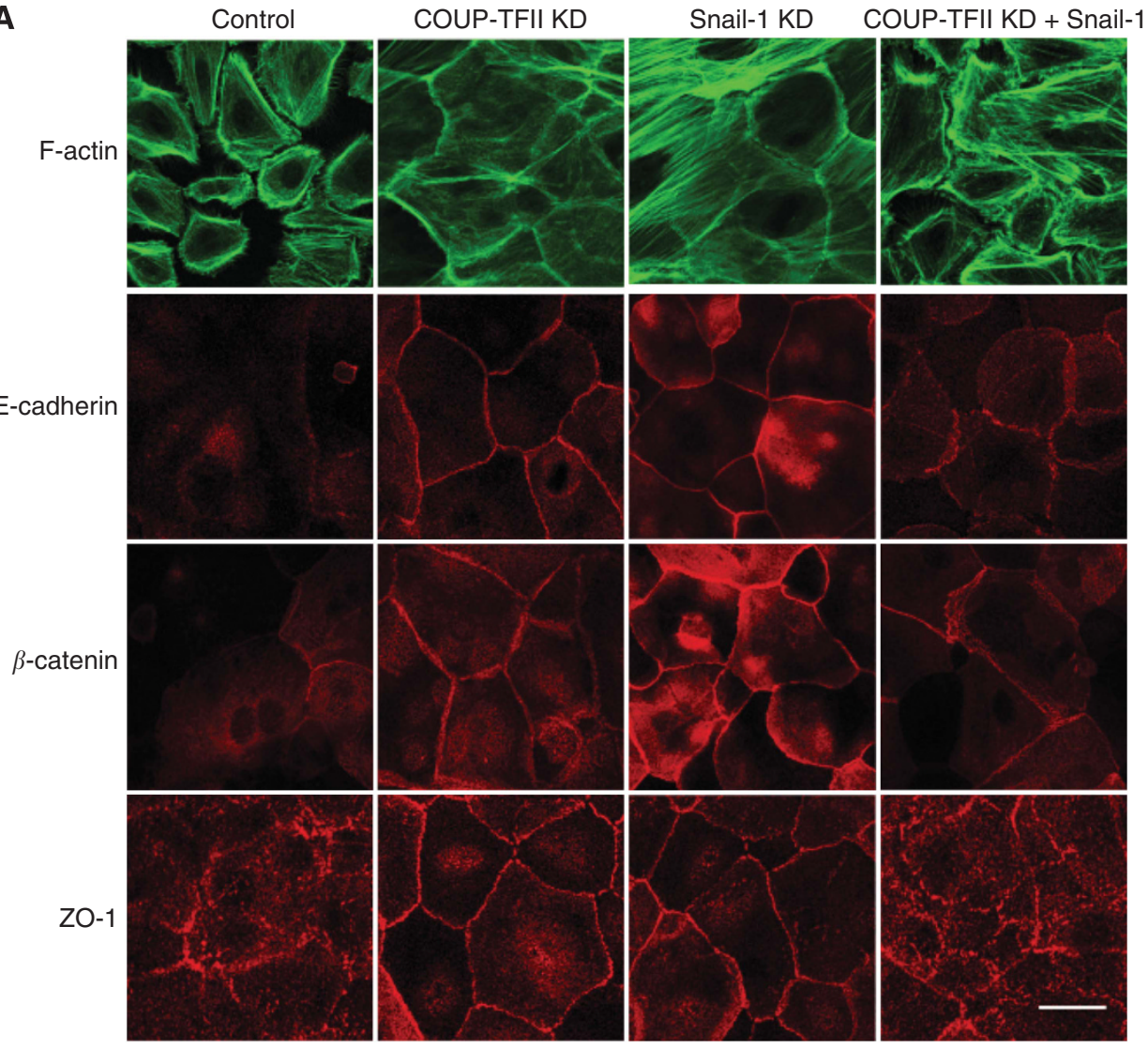

B
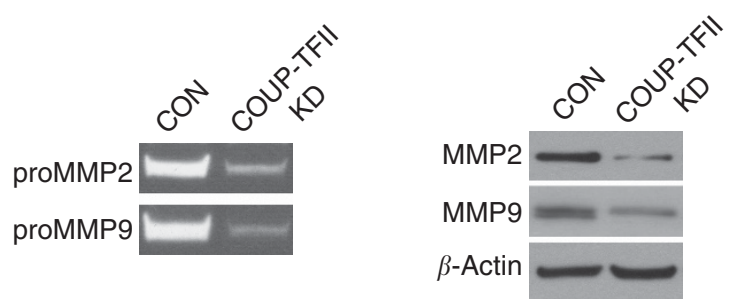

C
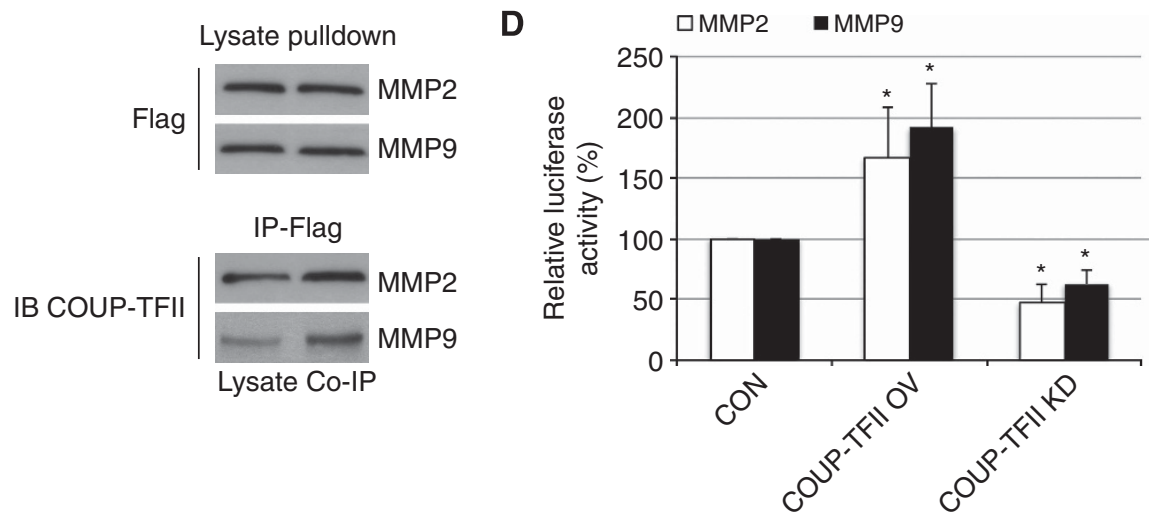

Figure 4. Chicken ovalbumin upstream promoter-transcription factor II regulates colon cancer cell invasion by regulating cadherins and MMPs. LOVO cells stably expressing control vector (con), shRNA against COUP-TFII (COUP-TFII KD), shRNA against Snail1 (Snail-1 KD), or COUP-TFII KD + Snail1-overexpressing plasmid were cultured. (A) Expression of F-actin, E-cadherin, $\beta$-catenin and ZO-1 by immunofluorescence. Bar, $20 \mu \mathrm{m}$. (B) Activity of proMMP2 and proMMP9 in LOVO cell supernatants determined by gelatinase zymography (left). Expression of MMP2 and MMP9 in LOVO cell cytoplasm by western blot (right). (C) Binding to the MMP2 or MMP9 promoter in control (CON) or COUP-TFIl knockdown (KD). Cells were transfected with Flag-tagged COUP-TFII. Promoter activity of MMP2 or MMP9 induced by co-expression of COUP-TFII-overexpressing vector. Pull-down assay and ChIP were used to test binding of COUP-TFII and MMP2 or MMP9 promoter. (D) Luciferase activities were measured in LOVO cells cotransfected with COUP-TFII overexpressing or shRNA against COUP-TFIl vector. ${ }^{\star} P<0.01$, compared to control. Biotin-labelled oligonucleotides were incubated with nuclear extracts from LOVO cells transiently transfected with COUP-TFII-overexpressing vector. Immobilised streptavidin was used to precipitate the oligonucleotide-transcription factor complexes. Protein-DNA complexes were analysed by immunoblotting using antibodies against FLAG and COUP-TFII. 
A

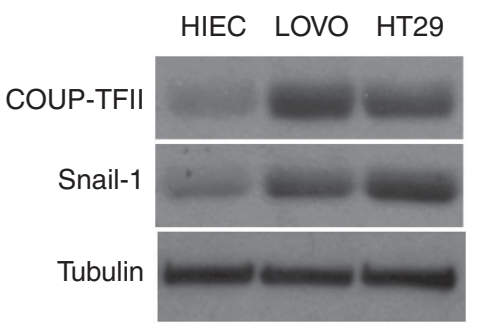

C

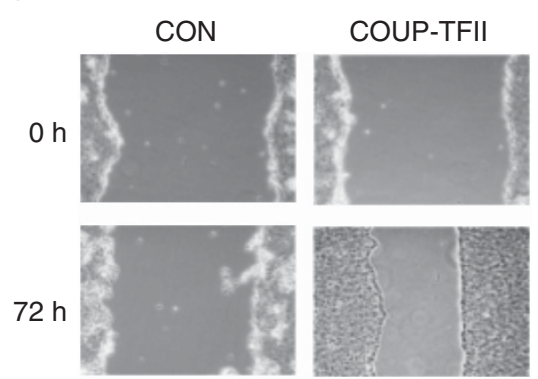

E

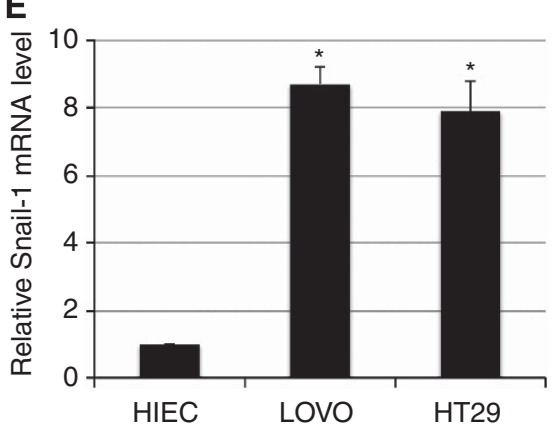

B

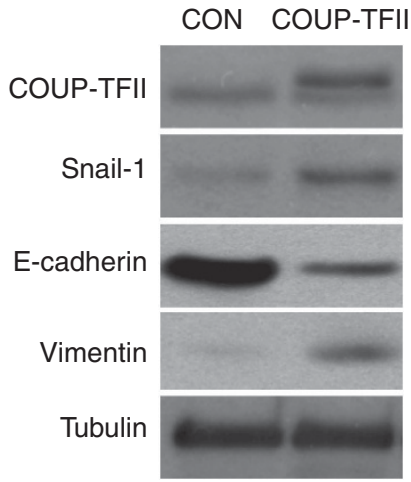

D

HIEC CON
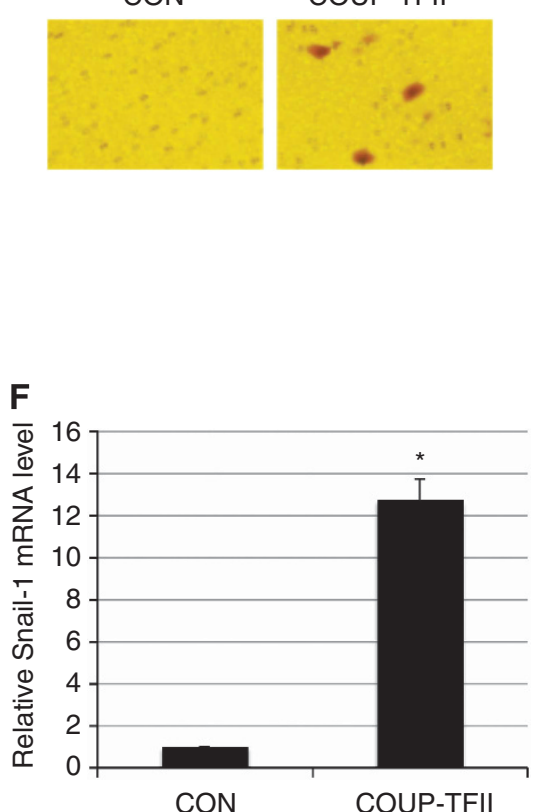

Figure 5. Overexpression of COUP-TFII in intestinal epithelial cells results in tumour characteristics. (A) Expression of COUP-TFII and Snail-1 in HIEC, LOVO and HT29 cells by western blot. (B) HIEC cells were transfected with a COUP-TFll-overexpressing plasmid (COUP-TFII), and cytoplasmic COUP-TFII and Snail-1 were examined by western blot. (C) Wound-healing assay of control and COUP-TFII-overexpressing HIEC cells showing wound width for percent closure of the original wound in triplicate plates. Similar results were obtained in three experiments. (D) Migrated control and COUP-TFIl-overexpressing cells that penetrated Matrigel-coated filters. (E) Snail-1 mRNA in HIEC, LOVO and HT29 cells was quantified by real-time PCR ( ${ }^{\star} P<0.01$ compared to HIEC). (F) Snail-1 mRNA in control and COUP-TFIl-overexpressing cells quantified by real-time PCR $\left({ }^{\star} P<0.01\right.$ compared to $\left.C O N\right)$.

repression them, thereby effecting related cellular features. Snaill could activate ctnnb1-b, Pparg1, Ucp3, hTERT, Mmp2 and Otx2, but repress JUNB, Cyp7a1, Cdh1 and Cdh2 gene.

\section{DISCUSSION}

In this study, we demonstrated that COUP-TFII is involved in colon cancer cell motility and metastasis mechanisms. Previous studies showed that ablation of COUP-TFII in adult mice markedly compromised neoangiogenesis, suppressed tumour growth in xenograft mouse models, and impaired tumour metastasis, indicating that COUP-TFII is an important regulator for pathologic neovascular responses (Qin et al, 2010).

Chicken ovalbumin upstream promoter-transcription factor II regulates colon cancer cells metastasis with Snaill. The incidences of tumours were similar between wild-type and COUP-TFII mutant mice, suggesting that COUP-TFII was not crucial for tumour initiation. However, metastatic tumours were observed only in wildtype, not in COUP-TFII mutant mice. Furthermore, in a liver metastasis model, metastatic tumours were found in the livers of mice injected with LOVO colon cancer cells, but not cells in which COUPTFII expression was suppressed, suggesting that COUP-TFII was important for tumour cell metastasis.

Our correlation studies indicated that COUP-TFII expression in tumour cells was significantly associated with Snaill expression. Univariate analysis indicated that COUP-TFII expression levels in colon cancer tissues predicted patient survival. Patients whose tumours had high levels of COUP-TFII and Snail expression showed significantly shorter survival than patients whose tumours had low expression of both proteins. In vitro, overexpression of COUP-TFII in normal intestinal epithelial cells enhanced cell migration and invasion. Moreover, suppression of both COUP-TFII and Snail-1 inhibited colon cancer cell migration and invasion and this inhibition could be partially abolished by overexpression of Snaill in COUP-TFII knockdown cells. These results suggested that COUP-TFII regulated colon cancer cell metastasis through Snail1. 
A

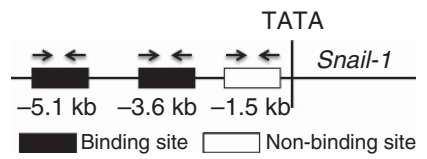

C

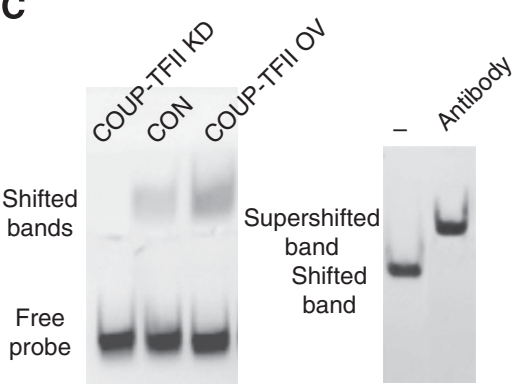

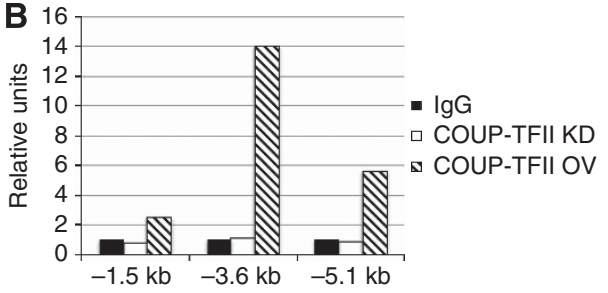

D

\begin{tabular}{lrcc}
\hline \multicolumn{4}{c}{ Expression fold changes } \\
\cline { 2 - 3 } Gene & CON & COUP-TFII KD & ChIP fold enrichment \\
\hline JUNB & -3.6 & 4.1 & 2.5 \\
Cyp7a1 & 0.9 & 1.3 & 1.5 \\
Ctnnb1-b & 1.6 & -0.3 & 1.2 \\
Pparg-1 & 2.1 & -1.7 & 1.9 \\
Ucp3 & 3 & -2.2 & 3.2 \\
hTERT & 2.7 & -1.8 & 2.4 \\
Mmp2 & 0.2 & -2.2 & 3.5 \\
Otx2 & 1.4 & -1.9 & 2.8 \\
Cdh1 & -2.3 & 2.6 & 1.8 \\
Cdh2 & -1.9 & 2.1 & 1.9 \\
\hline
\end{tabular}

Figure 6. Chicken ovalbumin upstream promoter-transcription factor II positively regulates Snail-1 expression through direct transcriptional activation. (A and B) Extracts of LOVO cells stably expressing control vector (CON), shRNA against COUP-TFII (COUP-TFII KD), or COUP-TFIIoverexpressing vector (COUP-TFII OV) were examined by chromatin immunoprecipitation with anti-COUP-TFII antibody or non-immune IgG and real-time PCR of Snail-1 promoter regions containing or lacking high-affinity COUP-TFIl-binding sites (black and white boxes in the map). Supershift assay was used by using antibody against COUP-TFII. - , control without antibody; antibody, with antibody against COUP-TFII (C) EMSA using LOVO cells stably expressing control vector (CON), COUP-TFII shRNA (COUP-TFII KD), or COUP-TFII-overexpressing vector (COUPTFII OV) and a FAM-labelled oligonucleotide with the COUP-TFII-binding site from Snail-1. For supershift assay, anti-COUP-TFII antibody. (D) After ChIP with anti-Snail-1 using transfected LOVO cells as in C, target genes were detected by quantitative real-time PCR.

Chicken ovalbumin upstream promoter-transcription factor II regulates cell junctions and matrix metalloproteinases in colon cancer cells independently of Snail1. We found that COUP-TFII was involved in the control of cell-cell interaction and the extracellular matrix. In both COUP-TFII-deficient or Snail1deficient LOVO cells, E-cadherin, $\beta$-catenin and ZO-1 were observed after addition of calcium-to-cell medium. However, only weak signals for the proteins were detected in control LOVO cells. Cell-to-cell contacts between COUP-TFII knockdown cells appeared to be defective after transfection with a Snail1-overexpressing plasmid, indicating that COUP-TFII regulated cell-to-cell junctions in colon cancer cells through Snaill. Chicken ovalbumin upstream promoter-transcription factor II promoted the expression and activity of MMP2 and MMP9 by directly binding to the promoters of their genes, and this effect was independent of Snaill.

Chicken ovalbumin upstream promoter-transcription factor II regulates Snail1 expression by transcription activation. Chicken ovalbumin upstream promoter-transcription factor II modulates gene expression by either activation or repression through direct binding to response elements in DNA or by binding to a second transcription factor in tissue-specific and gene-specific manners (Litchfield and Klinge, 2012). Genes activated by COUP-TFII include RA receptor b2 (RARb2, RARB2), phosphoenolpyruvate carboxykinase (PEPCK, PCK1), NGFI-A (Egr1), cholesterol 7a-hydroxylase (CYP7A1), PCK1, and Otx2 (De Martino et al, 2004). COUP-TFII binding to DRs may result in gene repression. Binding of COUP-TFII to DNA results in recruitment of corepressors such as nuclear corepressor (Bailey et al, 1997) and silencing mediator of retinoid and thyroid receptors. This results in repression of target genes such as PAX6, PPARg1 and PPARg2 (Okamura et al, 2009). In this study, inhibition of COUP-TFII expression repressed Snail1 in colon cancer cells. In normal intestinal epithelial cells, overexpression of COUP-TFII enhanced Snail1 expression at the protein and RNA levels. By ChIP, we found that COUP-TFII directly bound to the Snail1 promoter region. Binding activated transcription of Snail1 and other genes. In
Figure 6D, Snail1-activated ctnnb1-b, Mmp2 and Otx2 genes, which are related to carcinogenesis and metastasis process, but repress $C d h 1$ gene, which is related to cell junction and cell metastasis.

In conclusion, we presented results indicating that COUP-TFII functions in colon cancer cell metastasis through interaction with Snaill. COUP-TFII could be developed into a prognostic marker for colon cancer and is a potential target for colon cancer treatments.

\section{ACKNOWLEDGEMENTS}

This work was supported by the co-constructed program by Ministry of Health and Zhejiang Province (WKJ 2012-2-037), Zhejiang Province Welfare Technology Applied Research Program (2011C33245), Huzhou Welfare Technology Applied Research Program (2013GZ14), 973 Foundation (2013CB531606), National Science Foundation of China (81273282, 81202353, 81371786, 81302579), Shanghai Municipal Commission for Science and Technology (11JC1410902), Dingyuan Grant of Talent Development in Yangpu District, Wujieping Grant (320.6750.13147), Changhai Hospital (CH125530300) of Nanjing District (12MA056) and The Educational fund of SMMU (jgc2013023). We thank Dr Christine Tachibana for her efforts to edit this manuscript.

\section{CONFLICT OF INTEREST}

The authors declare no conflict of interest.

\section{REFERENCES}

Bailey PJ, Dowhan DH, Franke K, Burke LJ, Downes M, Muscat GE. (1997) Transcriptional repression by COUP-TF II is dependent on the C-terminal domain and involves the N-CoR variant, RIP13delta1. J Steroid Biochem Mol Biol 63: 165-174. 
Cano A, Pérez-Moreno MA, Rodrigo I, Locascio A, Blanco MJ, del Barrio MG, Portillo F, Nieto MA (2000) The transcription factor snail controls epithelial-mesenchymal transitions by repressing E-cadherin expression. Nat Cell Biol 2: 76-83.

De Martino MU, Alesci S, Chrousos GP, Kino T (2004) Interaction of the glucocorticoid receptor and the chicken ovalbumin upstream promoter-transcription factor II (COUP-TFII): implications for the actions of glucocorticoids on glucose, lipoprotein, and xenobiotic metabolism. Ann N Y Acad Sci 1024: 72-85.

De Martino MU, Bhattachryya N, Alesci S, Ichijo T, Chrousos GP, Kino T (2004) The glucocorticoid receptor and the orphan nuclear receptor chicken ovalbumin upstream promoter-transcription factor II interact with and mutually affect each other's transcriptional activities: implications for intermediary metabolism. Mol Endocrinol 18: 820-833.

Gelfi C, Vigano A, De Palma S, Righetti PG, Righetti SC, Corna E, Zunino F (2002) Single-strand conformation polymorphism for p53 mutation by a combination of neutral $\mathrm{pH}$ buffer and temperature gradient in capillary electrophoresis. Electrophoresis 23: 1517-1523.

Hamada K, Monnai M, Kawai K, Nishime C, Kito C, Miyazaki N, Ohnishi Y, Nakamura M, Suemizu H (2008) Liver metastasis models of colon cancer for evaluation of drug efficacy using NOD/Shi-scid IL2Rgammanull (NOG) mice. Int J Oncol 32: 153-159.

Kieback DG, Runnebaum IB, Moebus VJ, Kreienberg R, McCamant SK, Edwards CL, Jones LA, Tsai MJ, O’Malley BW (1993) Chicken ovalbumin upstream promoter-transcription factor (COUP-TF): an orphan steroid receptor with a specific pattern of differential expression in human ovarian cancer cell lines. Gynecol Oncol 51: 167-170.

Kieback DG, Runnebaum IB, Moebus VJ, Kreienberg R, McCamant SK, Edwards CL, Jones LA, Tsai MJ, O’Malley BW (1996) Chicken ovalbumin upstream promoter-transcription factor (COUP-TF) expression in human endometrial cancer cell lines. Anticancer Res 16: 3371-3376.

Kudo-Saito C, Shirako H, Takeuchi T, Kawakami Y (2009) Cancer metastasis is accelerated through immunosuppression during Snail-induced EMT of cancer cells. Cancer Cell 15: 195-206.

Lee CT, Li L, Takamoto N, Martin JF, Demayo FJ, Tsai MJ, Tsai SY (2004) The nuclear orphan receptor COUP-TFII is required for limb and skeletal muscle development. Mol Cell Biol 24: 10835-10843.

Lee KN, Jang WG, Kim EJ, Oh SH, Son HJ, Kim SH, Franceschi R, Zhang XK, Lee SE, Koh JT (2012) Orphan nuclear receptor COUPTFII negatively regulates BMP2-induced osteoblast differentiation through suppressing Runx2 activity. J Biol Chem 287: 18888-18899.

Li X, Deng W, Lobo-Ruppert SM, Ruppert JM (2007) Gli1 acts through Snail and E-cadherin to promote nuclear signaling by beta-catenin. Oncogene 26: 4489-4498.

Litchfield LM, Klinge CM (2012) Multiple roles of COUP-TFII in cancer initiation and progression. J Mol Endocrinol 49: R135-R148.

Mareel M (1984) Invasion, Experimental and Clinical Implications. pp 63Oxford University Press: Oxford, New York, Tokyo.

Nie J, Pei J, Blumenthal M, Pei D (2007) Complete restoration of cell surface activity of transmembrane-truncated MT1-MMP by a glycosylphosphatidylinositol anchor. Implications for MT1-MMPmediated prommp2 activation and collagenolysis in three-dimensions. J Biol Chem 282: 6438-6443.

Okamura M, Kudo H, Wakabayashi K, Tanaka T, Nonaka A, Uchida A, Tsutsumi S, Sakakibara I, Naito M, Osborne TF, Hamakubo T, Ito S, Aburatani H, Yanagisawa M, Kodama T, Sakai J (2009) COUPTFII acts downstream of Wnt/beta-catenin signal to silence PPARgamma gene expression and repress adipogenesis. Proc Natl Acad Sci USA 106: 5819-5824.

Pereira FA, Qiu Y, Zhou G, Tsai MJ, Tsai SY (1999) The orphan nuclear receptor COUP-TFII is required for angiogenesis and heart development. Genes Dev 13: 1037-1049.

Prahalad P, Dakshanamurthy S, Ressom H, Byers SW (2010) Retinoic acid mediates regulation of network formation by COUP-TFII and VE-cadherin expression by TGFbeta receptor kinase in breast cancer cells. PLoS One 5: e10023.
Qin J, Chen X, Xie X, Tsai MJ, Tsai SY (2010) COUP-TFII regulates tumor growth and metastasis by modulating tumor angiogenesis. Proc Natl Acad Sci USA 107: 3687-3692.

Qin J, Chen X, Yu-Lee LY, Tsai MJ, Tsai SY (2010) Nuclear receptor COUPTFII controls pancreatic islet tumor angiogenesis by regulating vascular endothelial growth factor/vascular endothelial growth factor receptor-2 signaling. Cancer Res 70: 8812-8821.

Shibata H, Ando T, Suzuki T, Kurihara I, Hayashi K, Hayashi M, Saito I, Kawabe H, Tsujioka M, Mural M, Saruta T (1998) Differential expression of an orphan receptor COUP-TFI and corepressors in adrenal tumors. Endocr Res 24: 881-885.

Song CH, Lee HJ, Park E, Lee K (2012) The chicken ovalbumin upstream promoter-transcription factor II negatively regulates the transactivation of androgen receptor in prostate cancer cells. PLoS One 7: e49026.

Steeg PS (2006) Tumor metastasis: mechanistic insights and clinical challenges. Nat Med 12: 895-904.

Sugiyama T, Wang JC, Scott DK, Granner DK (2000) Transcription activation by the orphan nuclear receptor, chicken ovalbumin upstream promotertranscription factor I (COUP-TFI). Definition of the domain involved in the glucocorticoid response of the phosphoenolpyruvate carboxykinase gene. J Biol Chem 275: 3446-3454.

Wang Z, Jin H, Xu R, Mei Q, Fan D (2009) Triptolide inhibits proliferation and migration, enhance apoptosis in inflammatory bowel diseases induced colorectal cancer via Rac1/JAK/STAT3 pathway. Exp Mol Med 4: 717-727.

Wang Z, Liu L, Wang M, Shen M, Li J, Liu J, Li C, Xin C, Zhu S, Mei Q, Wang Y (2012) NOTCH1 regulates migration and invasion of skin cancer cells by E-cadherin repression. Mol Cell Biochem 362: $35-41$.

Wang Z, Zhu S, Shen M, Liu J, Wang M, Li C, Wang Y, Deng A, Mei Q (2013) STAT3 is involved in esophageal carcinogenesis through regulation of Oct-1. Carcinogenesis 34: 678-688.

Wu Q, Li Y, Liu R, Agadir A, Lee MO, Liu Y, Zhang X (1997) Modulation of retinoic acid sensitivity in lung cancer cells through dynamic balance of orphan receptors nur77 and COUP-TF and their heterodimerization. EMBO J 16: 1656-1669.

Xie X, Qin J, Lin SH, Tsai SY, Tsai MJ (2011) Nuclear receptor chicken ovalbumin upstream promoter-transcription factorii (COUP-TFII) modulates mesenchymal cell commitment and differentiation. Proc Natl Acad Sci USA 108: 14843-14848.

Xu Z, Pei L, Wang L, Zhang F, Hu X, Gui Y (2013) Snail1-dependent transcriptional repression of Cezanne2 in hepatocellular carcinoma. Oncogene 33: 2836-2845.

Yamazaki T, Suehiro J, Miyazaki H, Minami T, Kodama T, Miyazono K, Watabe T (2013) The COUP-TFII variant lacking a DNA-binding domain inhibits the activation of the Cyp7al promoter through physical interaction with COUP-TFII. Biochem J 452: 345-357.

You LR, Lin FJ, Lee CT, DeMayo FJ, Tsai MJ, Tsai SY (2005) Suppression of Notch signaling by the COUP-TFII transcription factor regulates vein identity. Nature 435: 98-104.

You LR, Takamoto N, Yu CT, Tanaka T, Kodama T, Demayo FJ, Tsai SY, Tsai MJ. (2005) Mouse lacking COUP-TFII as an animal model of Bochdalek-type congenital diaphragmatic hernia. Proc Natl Acad Sci USA 102: 16351-16356.

Zhang K, Corsa CA, Ponik SM, Prior JL, Piwnica-Worms D, Eliceiri KW, Keely PJ, Longmore GD (2013) The collagen receptor discoidin domain receptor 2 stabilizes SNAIL1 to facilitate breast cancer metastasis. Nat Cell Biol 15: 677-687.

This work is published under the standard license to publish agreement. After 12 months the work will become freely available and the license terms will switch to a Creative Commons AttributionNonCommercial-Share Alike 3.0 Unported License. 